\title{
Gabriel Warburg
}

Islam, Nationalism and Communism in a Traditional Society: The Case of Sudan Frank Cass., London, 1978, $253 \mathrm{~S}$.

Professor Warburg, Historiker an der Universität von Haifa, hat mit dieser gut recherchierten Studie die wohl wichtigste Analyse vom Aufstieg und Sturz der kommunistischen Partei im Sudan (KPS) vorgelegt. Er rekonstruiert den Kampf um nationale Unabhängigkeit im Sudan vom britisch-ägyptischen Kondominium, der von den beiden großen, bis heute miteinander rivalisierenden Religionsgemeinschaften bestimmt war: den Mahdisten und der Khatmiyya-Sekte. Warburg versucht zu erklären, wieso eine kommunistische Kaderpartei (mit nur wenigen eingeschriebenen Mitgliedern, aber mit größeren Zahlen von Wählern unter Eisenbahnarbeitern, Gezira-Bauern und der "Intelligentsia") in einer muslemisch geprägten Gesellschaft vor allem in Krisenzeiten eine so bedeutende Rolle spielen konnte - bis zum Juli 1971, als Präsident Numeiri zum entscheidenden Schlag gegen die KPS ausholte. Zu dieser Zeit war die Partei allerdings schon gespalten - zerstritten über die Frage, ob sie mit der sich sozialistisch nennenden Einheitspartei der regierenden Militärjunta (SSU) verschmelzen sollte oder nicht.

Warburg erklärt die relativ große Bedeutung der KPS in den 60er Jahren mit zwei Hauptargumenten: zum einen unterstützten Sudanesen die KPS, weil sie damit gegen die religiösen Sekten protestieren wollten (ohne selbst der kommunistischen Ideologie anzuhängen), zum anderen war es die einzige politische Kraft, die seit der Unabhängigkeit eine föderative Konfliktlösung für die Südsudanfrage gefordert hatte.

Zusammen mit dem wertvollen Dokumentenanhang, der auch einen selbstkritischen Bericht des Zentralkomitees der KPS vom Herbst 1971 enthält, gehört diese Analyse zu den unentbehrlichen Grundlagen für das Verständnis der so widersprüchlichen und konfliktreichen Geschichte des modernen Sudan.

Rainer Tetzlaff

\section{Klaus Glaubitt/Bernhard Lageman}

Arabische Integrationsexperimente. Der Sudan als Bewährungsfeld arabischer Produktions- und Entwicklungsintegration

Bochumer Materialien zur Entwicklungsforschung und Entwicklungspolitik, Band 16, Horst Erdmann Verlag, Tübingen, Basel, 1980, 336 S., DM 32,-

Die Autoren sind der nach wie vor politisch aktuellen Frage nachgegangen, wie Investitionen der ölreichen arabischen Nachbarstaaten dem Sudan bei der Verwirklichung seiner "Brotkorb"-Strategie helfen könnten. Um hierauf eine Antwort zu geben, werden zunächst die Entwicklungsziele des Sudans unter integrationstheoretischen Fragestellun- 